\title{
Determination of gallic acid using poly(glutamic acid): graphene modified electrode
}

\author{
J JENCY FEMINUS, R MANIKANDAN, S SRIMAN NARAYANAN and P N DEEPA* \\ Department of Analytical Chemistry, School of Chemical Sciences, University of Madras, Guindy Campus, \\ Chennai 600 025, Tamilnadu, India \\ E-mail: pndeepa@hotmail.com
}

MS received 25 September 2018; revised 9 December 2018; accepted 18 December 2018; published online 19 January 2019

\begin{abstract}
Gallic acid (GA) is one of the main phenolic components occurring naturally in plants and has been a subject of increasing interest owing to its antioxidant, anti-mutagenic and anti-carcinogenic properties. The present work describes a rapid and cost-effective analytical procedure for the determination of gallic acid. PolyGlu/rGO electrode was fabricated by the electro-polymerisation of glutamic acid on reduced graphene oxide (rGO) modified paraffin impregnated graphite electrode (PIGE). The modified electrode was characterized by SEM, AFM and ATR-IR. The electrochemical behavior of gallic acid at the modified sensor was studied by voltammetric and amperometric techniques under optimized conditions in $\mathrm{pH} 5$ acetate buffer. The electrode showed good linear response towards the determination of gallic acid over the range of $0.03-480 \mu \mathrm{M}$ with $0.01 \mu \mathrm{M}$ as the detection limit for voltammetric technique and the amperometric technique showed a linear range of $1-17 \mu \mathrm{M}$ with $0.33 \mu \mathrm{M}$ as the detection limit. The electrode also showed good stability and reproducibility with a sensitivity of $0.97 \mu \mathrm{M} / \mu \mathrm{A}$. The proposed method can be applied to detect GA in real samples with satisfactory results.
\end{abstract}

Keywords. Poly glutamic acid; modified electrode; gallic acid and electrochemical sensor.

\begin{tabular}{ll}
\multicolumn{2}{l}{ Abbreviations } \\
rGO & Graphene \\
Poly-Glu & Poly glutamic acid \\
GA & Gallic acid
\end{tabular}

\section{Introduction}

Gallic acid (GA) also known as 3,4,5-trihydroxy benzoic acid belongs to a large family of secondary polyphenolic metabolites widely present in the plant kingdom. It occurs in natural products such as gallnut, blueberries, apples, flaxseeds, tea leaves, oak bark, walnuts and watercress. It possesses antioxidant, antiinflammatory, anti-microbial, radical scavenging properties and also DNA polymerase and ribonucleotide reductase activity. ${ }^{1,2}$ Its supplements are available as capsules, ointments and liquid extracts and have been used traditionally to treat a variety of ailments. Gallic acid is widely used in processed food, cosmetics and food packing materials as it prevents rancidity due to lipid peroxidation and spoilage. ${ }^{3}$ It is usually

\footnotetext{
*For correspondence
}

obtained through the alkaline or acid hydrolysis of tannins or hydrolysis of spent broths derived from Penicillium glaucum or Aspergillus niger. It has also been reported to possess cytotoxic effect against isolated hepatocytes. ${ }^{4,5}$ Given its biological importance gallic acid detection becomes pertinent. ${ }^{6,7}$

Graphene is the fundamental building element of many carbon allotropes including graphite, charcoal, carbon nanotubes, buckminster fullerene and other buckyballs. Graphene comprises a single layer of sixatom rings in a honeycomb network and can be conceptually considered as a true planar aromatic macromolecule. ${ }^{8}$ Graphene oxide exhibits interesting optical properties, ${ }^{9}$ chemical versatility and the tunable functional groups on the Graphene oxide (GO) surface makes GO an ideal platform to immobilize a variety of biomolecules including nucleic acids, peptides, proteins and has demonstrated its potential in electrochemical biosensors applications. ${ }^{10-12}$ Tailoring the electronic solid state properties of these carbon allotropes through chemical functionalization would improve its catalytic performance. ${ }^{13}$

Recent research has focused attention towards polymer-modified electrodes as they possess propitious 
characteristics such as more active sites, excellent perm-selectivity, good stability and strong adherence towards electrode surface. ${ }^{14,15}$ Biopolymers prove to be more promising sensing platform in comparison to synthetic polymers as they are bio-compatible and biodegradable. ${ }^{16-18}$ Poly-Glutamic acid (Poly-Glu) is one such biopolymer with various biological functions and promising properties for basic and applied research. ${ }^{19-26}$ Poly-Glu is known to promote electron transfer and also provide conducting bridges. ${ }^{27-29}$ It consists of various units of Glutamic acid connected through $\gamma$-peptide linkages and the $\alpha$-carboxyl groups are free to bind with a wide range of compounds. ${ }^{29-31}$

Herein, the analytical utility of Poly-Glu/rGO modified electrode as a sensing platform has been reported for the selective determination of Gallic acid through a constructive combination of the large surface area of Graphene and the strong sensing ability of PolyGlutamic acid.

\section{Experimental}

\subsection{Chemicals and reagents}

Glutamic acid and Graphite powder were purchased from Sigma-Aldrich, USA. Graphite rods of $0.3 \mathrm{~cm}$ diameter and length of $4.0 \mathrm{~cm}$ were purchased from Aldrich, USA. All other reagents were of analytical grade and were used as received without any further purification. Doubly distilled water was used throughout the experiments.

\subsection{Instrumentation}

All electrochemical experiments were performed on a $\mathrm{CHI}$ 660B electrochemical workstation (CH Instruments, USA) comprising a conventional three-electrode system consisting of a platinum wire as an auxiliary electrode, saturated calomel as reference electrode and a bare Paraffin impregnated graphite electrode (PIGE) or PIGE/rGO/Poly-Glu modified electrode as the working electrode. All the experiments were carried out at room temperature. The SEM experiments were made on a VEGA3 TESCAN instrument, ATR-IR measurements using Thermo Scientific Nicolet iS5 with iD3 ATR-IR spectrometer and AFM images were recorded on MFP-3D Infinity ASYLUM Research instrument.

\subsection{Fabrication of Poly-Glu/rGO electrode}

2.3a Electrochemical reduction of GO: Initially, graphite rods were impregnated with paraffin according to the previously reported procedure to form PIGE. ${ }^{32}$ Then, an ethanolic solution of graphene oxide synthesized by modified Hummer's method ${ }^{33}$ was drop casted onto the surface of PIGE and allowed to dry for few hours at room temperature. The electrode was further subjected to a reduction potential

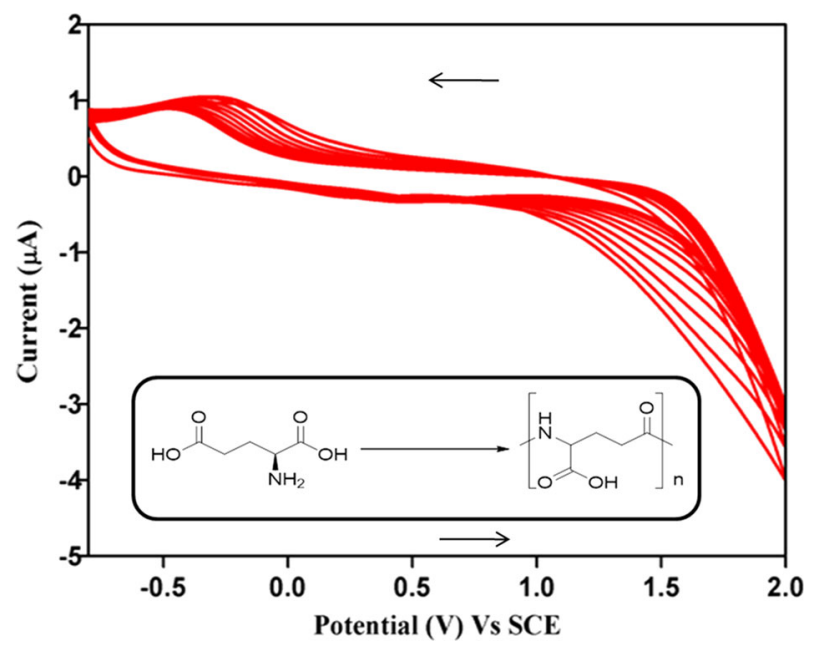

Figure 1. Electro-polymerization of Glutamic Acid on rGO electrode surface obtained by scanning potentials between -0.8 and $2 \mathrm{~V}$ for 20 cycles (scan rate of $50 \mathrm{mV} / \mathrm{s}$ in $\mathrm{PBS}$ at pH-7 containing 0.02M Glutamic acid).

of $-1.2 \mathrm{~V}$ over a period of $900 \mathrm{~s}$ in $0.1 \mathrm{M}$ Phosphate buffer solution (PBS) of pH-7.0 using chronoamperometry technique to obtain rGO/PIGE modified electrode. ${ }^{34}$

\section{$2.3 \mathrm{~b}$ Electro-polymerization of Glutamic acid on $r G O$} modified electrode surface: The rGO modified electrode was placed in PBS-7.0 containing 0.02 M Glutamic Acid and electropolymerization of glutamic acid was achieved by cycling potential from -0.8 to $2.0 \mathrm{~V}$ for 20 cycles $^{35}$ as shown in Figure 1. The electrode was then removed and the surface was rinsed with double distilled water to remove the excess monomer and the electrode obtained was labeled as PolyGlu/rGO modified electrode.

The surface coverage concentration of the poly-Glu/rGO modified electrode has been calculated by the following equation. ${ }^{36}$

$\tau=\frac{Q}{n F A}$

where $\tau$ indicates the surface coverage $\left(\mathrm{mol} \mathrm{cm}^{-2}\right)$, $\mathrm{Q}$ is the quantity of charge $(\mathrm{C}), \mathrm{n}$ is the number of electrons transfer, $\mathrm{A}$ is the electrode surface area $\left(\mathrm{cm}^{2}\right)$ and $\mathrm{F}$ is Faraday constant (96485.3329 $\mathrm{C} \mathrm{mol}^{-1}$ ). From equation (1), the surface coverage concentration of the poly-Glu/ rGO modified electrode was calculated to be $4.598( \pm 0.018) \times 10^{-9} \mathrm{~mol} \mathrm{~cm}^{-2}$.

\section{Results and Discussion}

\subsection{Electro-Polymerization of Glutamic acid on $r G O$ surface}

The Poly-Glu/rGO was prepared by placing the $\mathrm{rGO} /$ PIGE in PBS-7.0 containing 0.02 M Glutamic Acid and electro-polymerized at a potential range from -0.8 to $2.0 \mathrm{~V}$ for about 20 cycles. On the first scan, we 

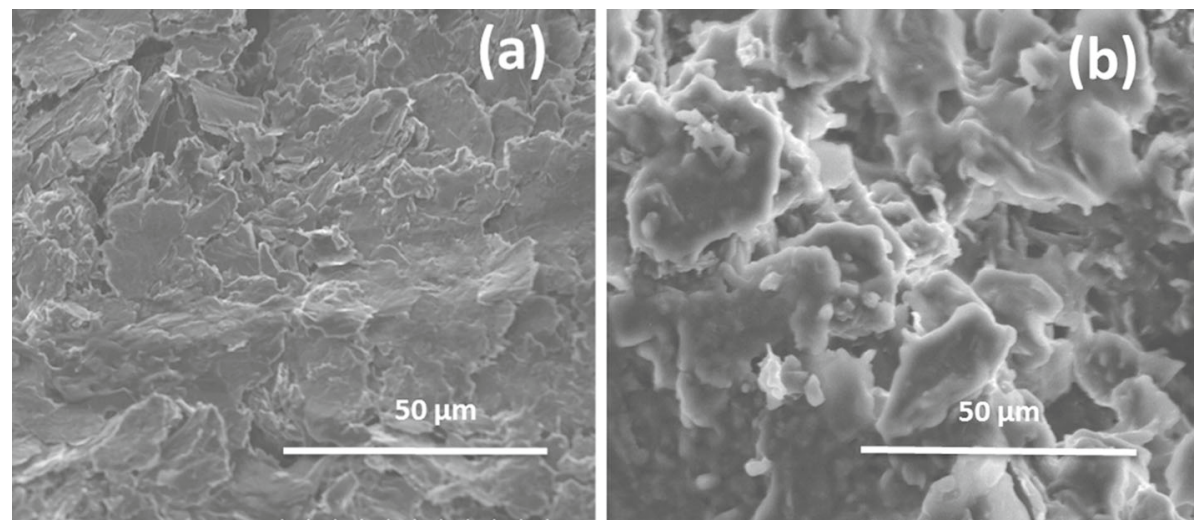

Figure 2. (a) SEM of the rGO modified surface and (b) Poly-Glu/rGO modified electrode surface.

observed an oxidation peak at about $1.65 \mathrm{~V}$ similar to the reports by some researchers ${ }^{35,37}$ which was attributed to the mass electro-polymerization of Glutamic acid on the electrode surface which almost vanished completely in the subsequent cycles. But, the anodic current increases gradually on cycling due to the formation of an electroactive layer of polymer film on the electrode surface and it remains almost constant after the $16^{\text {th }}$ cycle suggesting the level of saturation of polymer growth. Glutamic acid condenses due to the interaction between the amino group $\left(-\mathrm{NH}_{2}\right)$ and a carboxylic acid group $(-\mathrm{COOH})$. The Glutamic acid monomer undergoes deprotonation to form carboxylate anion $\left(-\mathrm{COO}^{-}\right)$and the amino group is oxidized to amino group radical cation. The interaction between these two ions results in the polymerization of Glutamic acid on the rGO electrode surface thus, leaving the remaining negatively charged carboxylate groups available for effective binding of the target moieties. ${ }^{35,36,38}$

\subsection{Characterization of the modified electrode}

The surface morphology of the Poly-Glu/rGO electrode was characterized by SEM techniques. Figure 2a shows the rGO modified electrode portraying the distinct sheets of Graphene which indicates that GO on the electrode surface has been electrochemically reduced to rGO. Figure $2 b$ shows the presence of Poly-Glutamic acid (Poly-Glu) over rGO, confirming that Glutamic acid has been successfully polymerized to Poly-Glu and it has grown regularly on the electrode surface.

The ATR-IR spectrum of Poly-Glu/rGO electrode is shown in Figure 3. The peaks located at around 1698 $\mathrm{cm}^{-1}$ and $1207 \mathrm{~cm}^{-1}$ correspond to the existence of $\mathrm{N}-\mathrm{H}$ and $\mathrm{COO}^{-}$groups, indicating that the condensation might have taken place between the amino group of one glutamic acid and the carboxylate group of another one and the remaining $\mathrm{COO}^{-}$group is retained in the

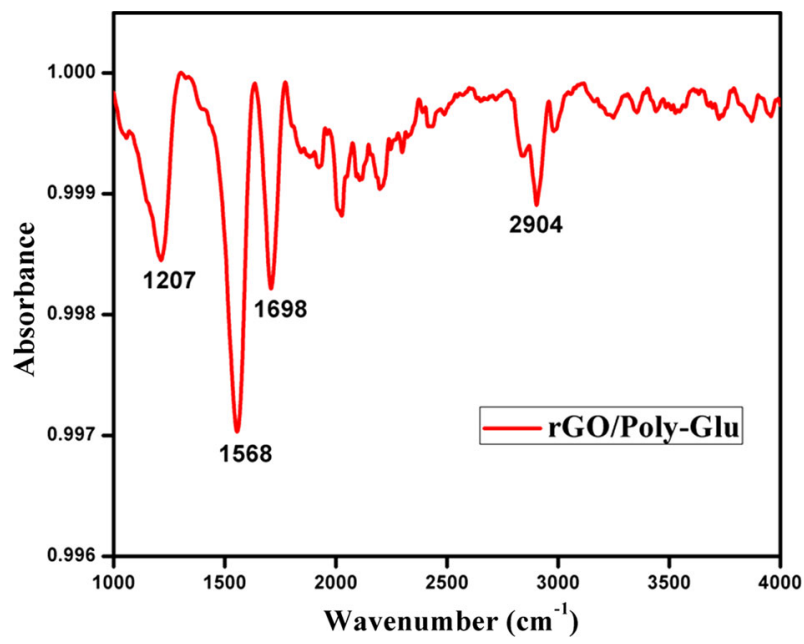

Figure 3. ATR-IR spectrum of Poly-Glu/rGO electrode surface.

monomer. ${ }^{35}$ Additionally, the peaks around $1568 \mathrm{~cm}^{-1}$ and $2904 \mathrm{~cm}^{-1}$ were attributed to the $\mathrm{C}=\mathrm{C}$ stretching in the quinonoid ring and asymmetric stretching of $\mathrm{C}-\mathrm{H}$ bonds, corresponding to that of rGO. ${ }^{39}$

Figure 4 depicts the typical AFM images of PolyGlu/rGO electrode. The images confirm the random distribution of Glutamic acid polymers on the electrode surface. The root mean square value was found to be $16.245 \mathrm{~nm}$. From this data, we can conclude that PolyGlutamic acid was successfully homogeneously coated onto the surface of rGO. As expected, a high coverage uniform layer of Poly-Glutamic acid has been formed on the electrode surface with large surface roughness. Thus, the as-prepared Poly-Glu/rGO electrode is applicable for further electrocatalytic applications. ${ }^{40,41}$

\subsection{Analytical performance of the Poly-Glu/rGO electrode}

3.3a Optimization of $\mathrm{pH}$ : Optimization of the electrochemical response of the modified electrode for 

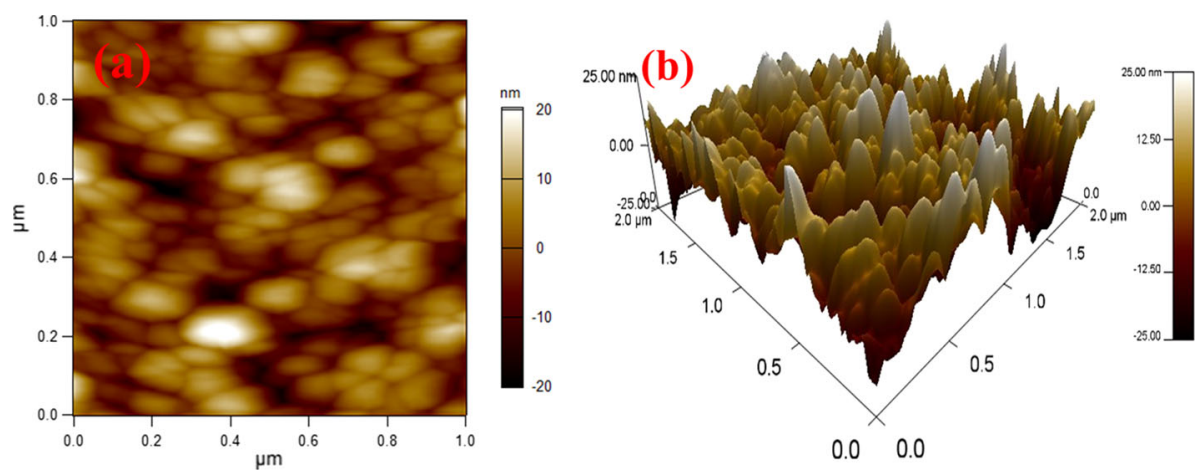

Figure 4. AFM images of Poly-Glu/rGO modified electrode surface.
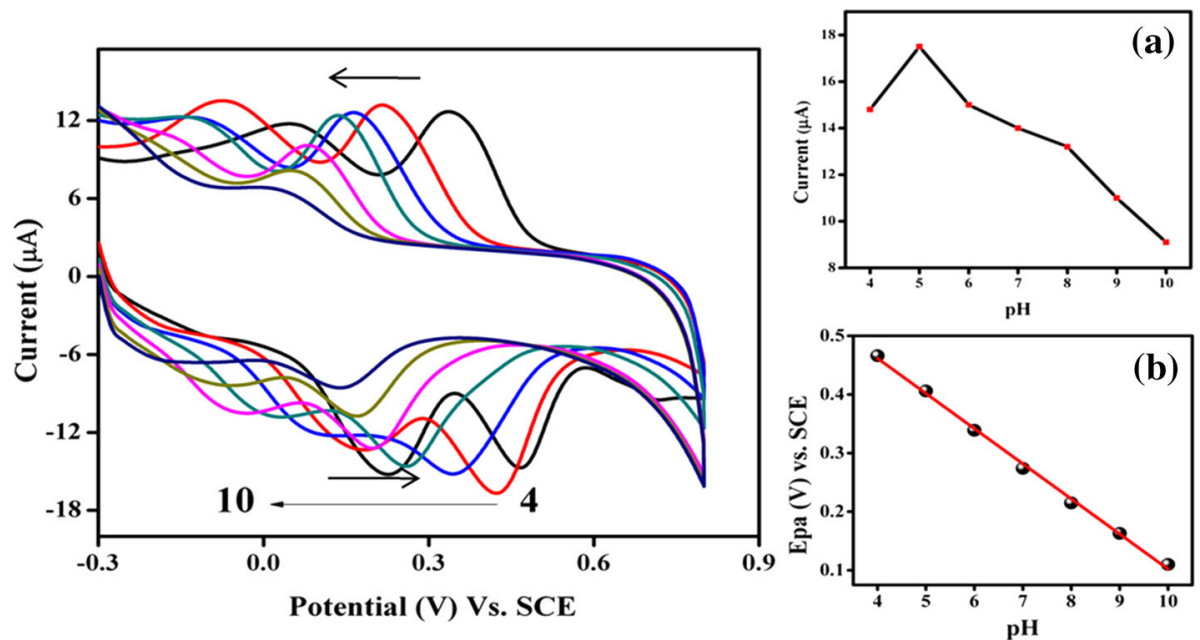

Figure 5. Cyclic Voltammograms of the Poly-Glu/rGO modified electrode for the electrocatalytic oxidation of Gallic acid $(7.0 \mu \mathrm{M})$ at various $\mathrm{pH}$. Scan rate: $50 \mathrm{mV} / \mathrm{s}$. Also shown are the (a) $\mathrm{pH}$ vs. Current and (b) $\mathrm{pH}$ vs. Potential plots.

Gallic acid was carried out. Figure 5 shows the current response for Poly-Glu/rGO electrode under varying conditions of $\mathrm{pH}$ (Scan rate: $50 \mathrm{mV} / \mathrm{s}$ ). The influence of $\mathrm{pH}$ on the electrochemical oxidation of GA was studied in the range from 4.0 to 10.0. On increasing the $\mathrm{pH}$ from 4.0 to 5.0, an increase in the peak current was observed which diminished on further increase in the $\mathrm{pH}$ from 5.0 to 10.0 , accompanied by a negative shift in the peak potential for GA oxidation as shown in the inset of Figure 5 (inset a). Thus, in order to achieve high oxidation current of GA, acetate buffer solution (ABS) at pH-5.0 was chosen for the further electrochemical determination of GA.

Figure 5(b) shows the plot of $\mathrm{pH}$ against oxidation of GA peak potential shift. The obtained linear equation is $\mathrm{E}_{\mathrm{pa}}(\mathrm{V})=(-0.05 \pm 0.021) \times+(0.59 \pm 0.03)\left(\mathrm{R}^{2}=\right.$ $0.998)$. The relationship between $\mathrm{pH}$ and peak potential is given by equation (2). ${ }^{42}$

$\frac{d E p}{d p H}=\frac{2.303 m R T}{n F}$
Here, $\mathrm{m}$ - number of protons, $\mathrm{n}$ - number of electrons, $\mathrm{R}$ - gas constant, $\mathrm{T}$ - temperature and $\mathrm{F}$ - Faraday constant. The ratio of the number of protons and electrons involved in the GA oxidation is $1: 1$. The number of electrons involved in the reaction has been calculated to be 2 .

3.3b Optimization of Scan rate: The effect of scan rate $(v)$ on the electrochemical responses of $5.0 \mu \mathrm{M}$ Gallic acid at the Poly-Glu/rGO electrode in ABS-5.0 was also studied using cyclic voltammetry. The voltammograms were recorded at a scan rate of $10-500 \mathrm{mV} / \mathrm{s}$. As shown in Figure 6, the oxidation current for GA increases with an increase in the scan rate. The oxidation peak currents for GA showed a linear relationship with the scan rate demonstrating a diffusion-controlled process. Furthermore, the plot of anodic peak currents $\left(i_{p a}\right)$ as a function of square root of the scan rate and plot of peak potential as a function of scan rate (Figure $6 a$ and $b$ ) in the range of 10 to $500 \mathrm{mV} / \mathrm{s}$ shows a linear relationship, with a linear regression coefficient 

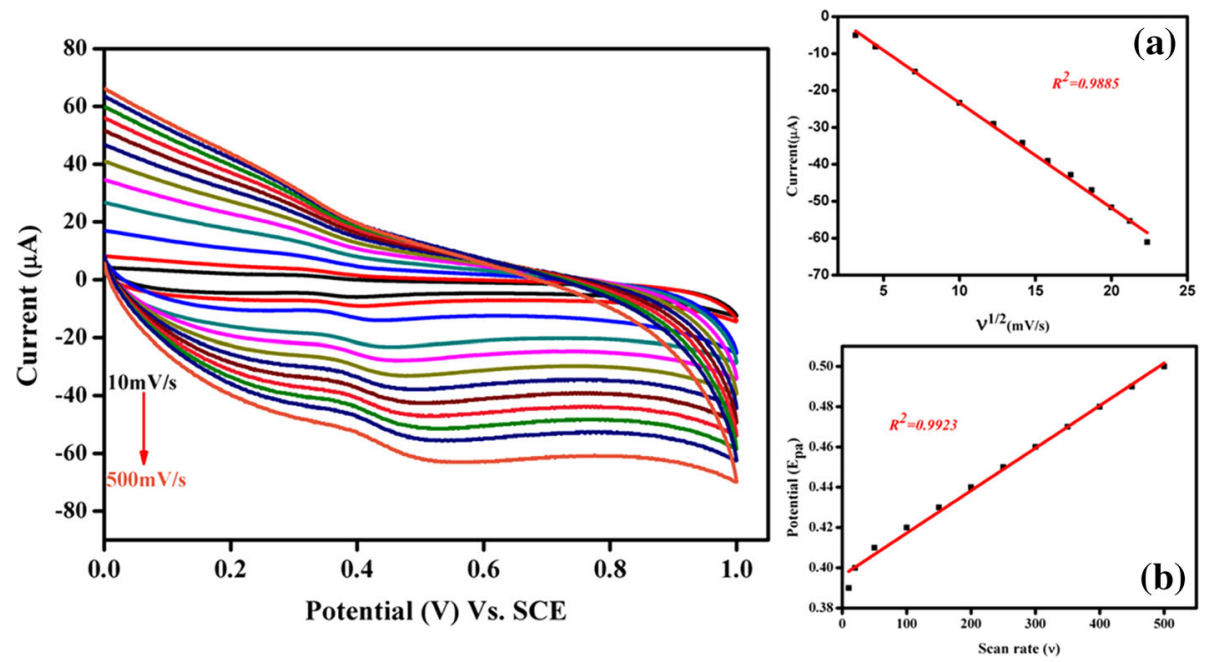

Figure 6. Effect of scan rate on the voltammogram for catalytic oxidation of $5.0 \mu \mathrm{M}$ Gallic acid at Poly-Glu/rGO modified electrode in $0.1 \mathrm{M}$ ABS at pH-5. (a) relationship between the square root of scan rate vs. current and (b) scan rate vs. potential plot.

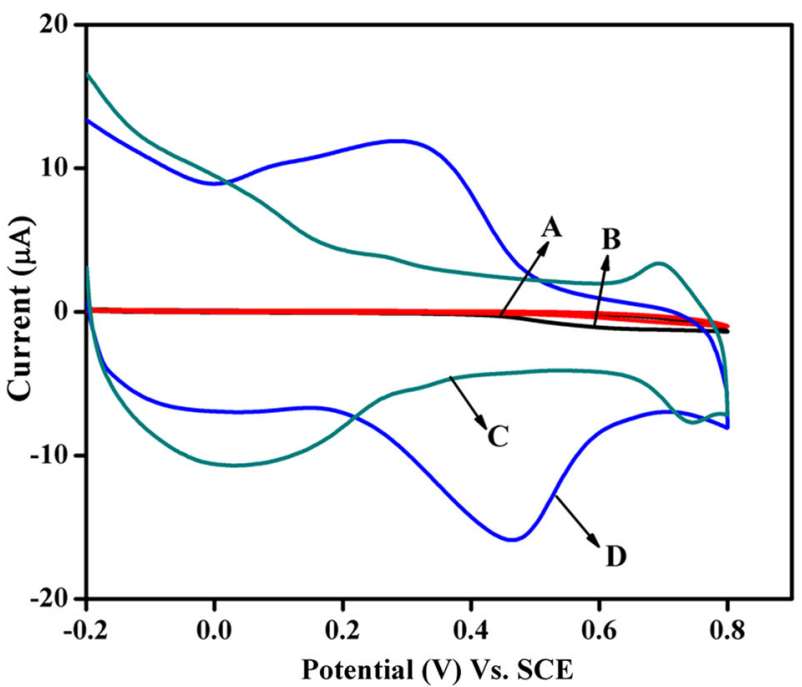

Figure 7. Cyclic voltammograms of the PIGE (A and B) and Poly-Glu/rGO electrode (C and D) without and with 10 $\mu \mathrm{M}$ GA respectively; Scan rate: $50 \mathrm{mV} / \mathrm{s}$, Supporting electrolye $0.1 \mathrm{M} \mathrm{ABS}(\mathrm{pH}-5)$.

$\left(\mathrm{R}^{2}\right)$ value of 0.988 and 0.992 . The $\mathrm{R}^{2}$ value of anodic peak currents $\left(\mathrm{i}_{\mathrm{pa}}\right)$ vs. the square root of the scan rate is almost equal to the theoretical value of 1.0, which is generally expected for a diffusion-controlled redox system and thus confirms the above-mentioned result. ${ }^{43}$

\section{3c Electrochemical behavior of bare and modified} electrodes: Figure 7 depicts the cyclic voltammograms for the unmodified PIGE electrode without GA (A) and in the presence of $10 \mu \mathrm{M}$ GA (B). Here the current values observed for the electrocatalytic oxidation of Gallic acid was hardly noticeable when compared

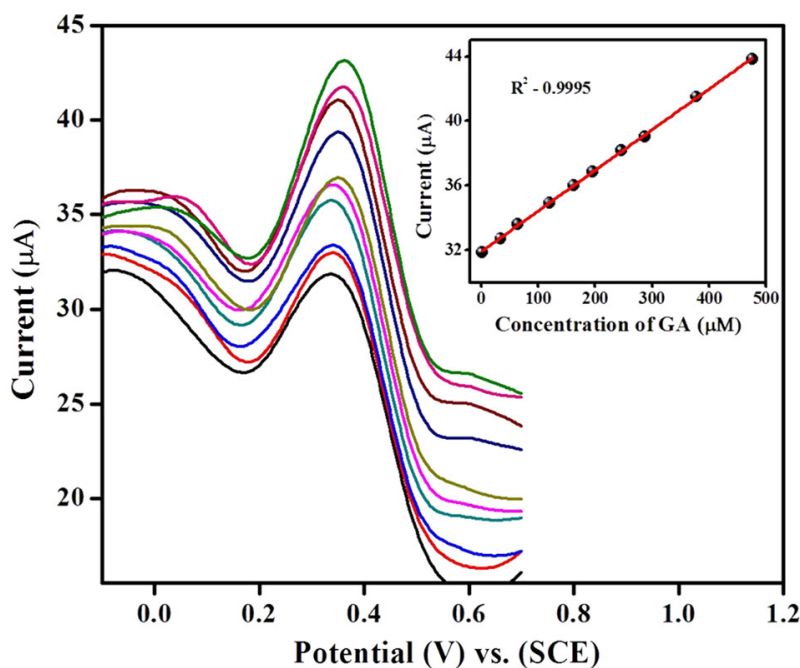

Figure 8. Differential pulse voltammograms obtained with the Poly-Glu/rGO modified electrode for incremental addition of GA in $0.1 \mathrm{M} \mathrm{ABS}$ at $\mathrm{pH}-5$ as supporting electrolyte and the corresponding calibration plot.

to the modified Poly-Glu/rGO electrode (C and D). At the modified electrode, distinct electrocatalytic behavior could be observed for a similar concentration of Gallic acid with enhanced anodic peak current values corresponding to the oxidation of Gallic acid at a potential of $0.5 \mathrm{~V}$.

\section{3d Electrochemical determination of Gallic Acid:} Under optimized conditions, Differential Pulse Voltammetry (DPV) was employed for the electrochemical determination of GA using Poly-Glu/rGO electrode. Figure 8 illustrates the DPV response of Poly-Glu/rGO electrode with increasing concentrations of GA at a 
Table 1. Comparison of the analytical performance of poly-Glu/rGO modified electrode towards GA determination with literature source.

\begin{tabular}{ccccc}
\hline Modified materials & Technique & Linear range $(\mu \mathbf{M})$ & LOD $(\mu \mathbf{M})$ & Ref \\
\hline $\mathrm{CPE}^{\circledR} / \mathrm{CNT}^{\#}$ & $\mathrm{DPV}$ & $0.5-150$ & 0.3 & 32 \\
$\mathrm{PEI}^{\$}-\mathrm{rGO} / \mathrm{GCE}$ & $\mathrm{CV}$ & $0.58-58$ & 0.41 & 33 \\
$\mathrm{PEP}^{\circ} / \mathrm{GCE}$ & $\mathrm{Ads} \mathrm{DPV}$ & $1-20$ & 0.66 & 34 \\
$\mathrm{Tyr}^{\wedge}-\mathrm{nAu}-\mathrm{GCE}$ & Amperometry & $25-900$ & 7 & 35 \\
$\mathrm{TH}^{*} / \mathrm{NiHCF} !$ & $\mathrm{CV}$ & $4.99-120$ & 1.66 & 36 \\
Poly glu/rGO & Amperometry & $\mathbf{1 - 1 7}$ & $\mathbf{0 . 5 3}$ & Present \\
& DPV & $\mathbf{0 . 0 3 - 4 8 0}$ & $\mathbf{0 . 0 0 9 5}$ & work \\
\hline
\end{tabular}

@-Carbon paste electrode.

\$- Polyethyleneimine.

\# - Carbon nanotubes

$\%$ - Polyepinephrine.

- Tyrosinase.

*- Thionine.

!- Nickel hexacyanoferrate.
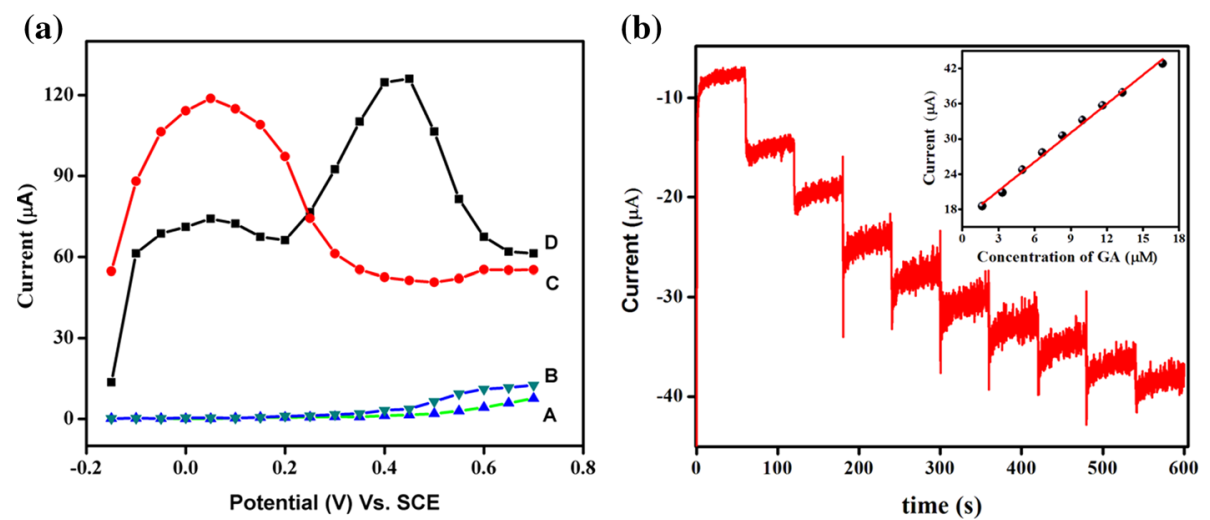

Figure 9. (a) Hydrodynamic voltammetric response of bare electrode (A and $\mathrm{B}$ ) and Poly-Glu/rGO modified electrode (C and D) in the absence and presence of $110 \mu \mathrm{M}$ GA, respectively, in $0.1 \mathrm{M}$ acetate buffer at pH-5.0 under stirring condition of $300 \mathrm{rpm}$, scan rate:50 mV/s. (b) Chronoamperometric response of Poly-Glu/rGO modified the electrode on successive addition of GA in $0.1 \mathrm{M}$ acetate buffer at pH-5.0 under the stirring condition of $300 \mathrm{rpm}$. Inset figure is the corresponding calibration plot.

potential window of -0.2 to $1.2 \mathrm{~V}$. The electrocatalytic oxidation of GA was investigated in the concentration range of $0.03-480 \mu \mathrm{M}$ with $0.1 \mathrm{M} \mathrm{ABS}-5.0$ as the background electrolyte.

A sharp and well-defined peak was observed for the oxidation of GA and the peak current increased proportionally with increasing concentration of GA. The calibration plot of peak currents for the oxidation vs. GA concentrations was found to be linear in the concentration range of $0.03-480.0 \mu \mathrm{M}$ (Figure 8 inset) with a linear regression coefficient value of $\left(\mathrm{R}^{2}\right) 0.999$ and the detection limit was found to be $0.01 \mu \mathrm{M}$. The sensitivity of Poly-Glu/rGO electrode was found to be 0.97 $\mu \mathrm{M} / \mu \mathrm{A}$. The obtained linear range is larger than literature reports as shown in Table $1 .{ }^{44-48}$ This demonstrates the good electrocatalytic activity of the poly-Glu/rGO electrode for GA.

\section{3e Determination of Gallic acid under dynamic con-} ditions: In order to characterize the performance of Poly-Glu/rGO electrode for the determination of GA in flow systems and evaluate the influence of flow conditions on the catalytic oxidation of GA as a function of the applied potential, the hydrodynamic study was carried out. Figure 9a shows the hydrodynamic response of bare electrode (Curve A and B) in the presence of $110.0 \mu \mathrm{M}$ of GA and Poly-Glu/rGO modified electrodes (Curve $C$ and D) respectively in the presence of 110.0 $\mu \mathrm{M}$ of GA in $0.1 \mathrm{M} \mathrm{ABS}-5.0$, at a scan rate $50 \mathrm{mV} / \mathrm{s}$ under stirring condition. It has been observed that the Poly-Glu/rGO electrode showed a good electrochemical response at $0.4 \mathrm{~V}$ for the catalytic oxidation of GA, whereas the bare and GO modified electrodes did not show any considerable current response under similar conditions. The rGO electrode favored GA oxidation 
at very low potential however, the sensitivity was poor. The electrocatalytic activity of Poly-Glu/rGO surface permitted convenient determination of GA with high sensitivity. Thus, a potential of $0.4 \mathrm{~V}$ was fixed for the amperometric studies.

3.3f Amperometric determination of GA: The amperometric response of Poly-Glu/rGO electrode towards the electrocatalytic oxidation of GA was analyzed by carrying out the analysis under stirring conditions. The maximum potential value of $0.4 \mathrm{~V}$ obtained from the hydrodynamic studies was fixed for the amperometric determination of GA in 0.1 M ABS-5.0. Figure $9 \mathrm{~b}$ shows the amperometric response of GA in the concentration range of 1.0-17.0 $\mu \mathrm{M}$. Here the concentration range was much reduced compared to the differential pulse voltammetric response (section 3.3c) with the modified electrode. This may be due to the mass transfer of the analyte towards the surface under stirring conditions. Each stepwise addition of GA was accompanied by a sharp increase in the current. The electrode also showed a fast response time of about $3 \mathrm{~s}$. The inset calibration plot represents the linear relationship between the catalytic current and GA concentration. The rapid electrochemical response of Poly-Glu/rGO electrode towards the electrocatalytic oxidation of GA reveals its viable application as a potent electrochemical sensor in flow systems.

\subsection{Interference studies}

The effect of various interfering species on the determination of GA using Poly-Glu/rGO electrode was examined in order to assess its possible analytical applications. The selectivity of the sensor in the presence of range of compounds including polyphenols and neurotransmitters (catechol (CC), hydroquinone (HQ), resorcinol (RC), dopamine (DA), ascorbic acid (AA), uric acid (UA) and catechin (CT) were studied since these compounds have an oxidation potential very close to that of GA. ${ }^{49}$ The interference studies were carried out by recording the current response of GA in the presence of equal or excess concentration of the interfering species. The Poly-Glu/rGO electrode showed no considerable deviations in the current response of GA in the presence of $\mathrm{CC}, \mathrm{HQ}, \mathrm{RC}, \mathrm{CT}$ and $\mathrm{AA}$ ions. However, the results as shown in Figure 10 indicate that UA and DA could be oxidized at the modified electrode but the potentials were far away from that of GA at $0.17 \mathrm{~V}$ and $0.85 \mathrm{~V}$ respectively. Also, there was no considerable increase in the oxidation current on further additions of UA and DA. Hence, the oxidation of GA in presence of UA and DA could be carried out without any considerable interference. The electrode modification

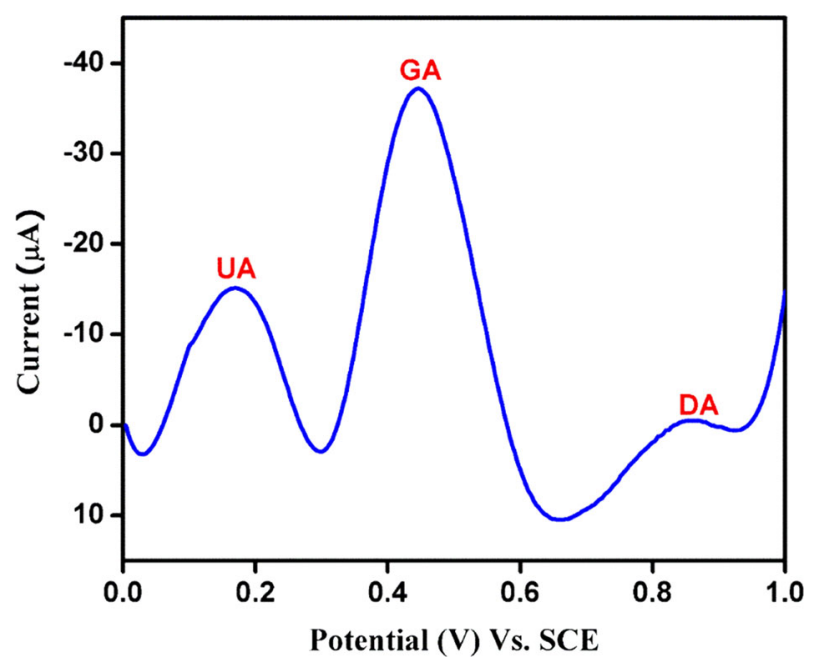

Figure 10. DPV plot of Poly-Glu/rGO electrode in $0.1 \mathrm{M}$ ABS (pH-5) containing $300 \mu \mathrm{M}$ GA, $600 \mu \mathrm{M}$ UA and 600 $\mu \mathrm{M}$ DA.

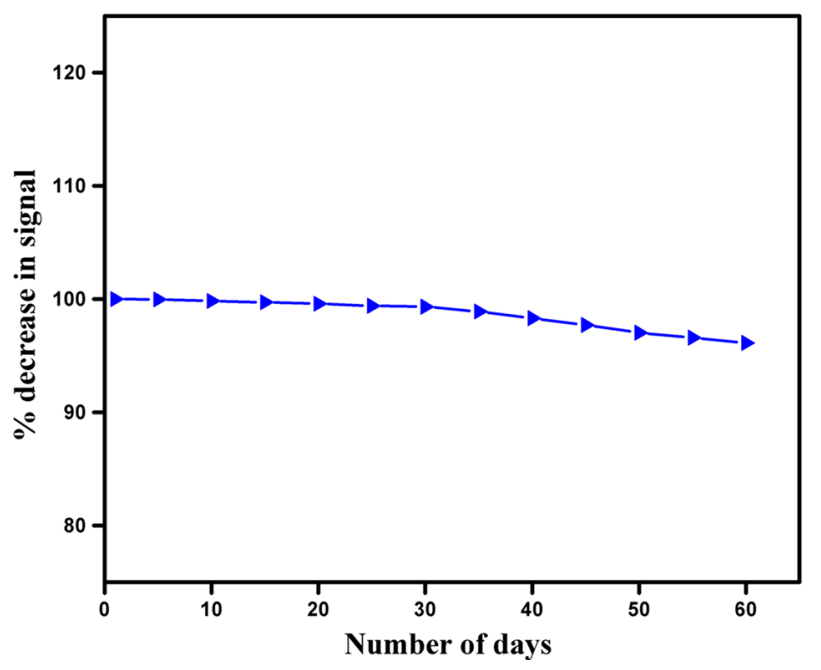

Figure 11. Storage stability of Poly-Glu/rGO electrode over a period of 60 days.

protocol thus provides for strong interactions with GA favouring its selective detection.

\subsection{Stability and reproducibility Poly-Glu/rGO electrode}

The modified electrode was placed in acetate buffer (ABS-5) once the experiment is complete and scanned until the GA oxidation peak disappears. The modified electrode was utilized to study the percentage of change in oxidation current of GA over a period of 4 weeks and the current changes were monitored. A small decrease in current was observed over this period (less than $1 \%( \pm 0.001)$ from initial current). Although the current response decreased gradually on 
Table 2. Determination of GA in green tea samples using poly-Glu/rGO modified electrode.

\begin{tabular}{lcccc}
\hline Sample ID & Added $(\mu \mathrm{M})$ & Found $(\mu \mathrm{M})$ & Recovery $(\%)$ & RSD $(\%)^{*}$ \\
\hline I & 5 & $5.2( \pm 0.02)$ & 104 & 2.36 \\
& 15 & $15.08( \pm 0.01)$ & 100.5 & 1.89 \\
II & 7 & $6.8( \pm 0.03)$ & 97.1 & 1.98 \\
& 20 & $20.1( \pm 0.025)$ & 100.5 & 2.35 \\
\hline
\end{tabular}

$*$ RSD reported for three parallel determinations $(n=3)$.

storage, it retained almost $95 \%$ of its initial response after 2 months (Figure 11). This indicates that the rGO/Poly-Glu electrode is suitable for long-term applications. The electrode was stored in a refrigerator at 4 ${ }^{\circ} \mathrm{C}$ when not in use.

\subsection{Real sample analysis}

The modified electrode was employed for the estimation of GA in two different brands of green tea samples by the voltammetric method under optimized conditions. The green tea samples were purchased from the local markets. The tea samples were extracted by a simple filtration method. About $100 \mathrm{mg}$ of dried and powered green tea leaves were transferred to $20 \mathrm{~mL}$ of double distilled water followed by boiling at $80{ }^{\circ} \mathrm{C}$ for $15 \mathrm{~min}$ then allowed to cool at room temperature. The extract was filtered using Whatman 42 filter paper and transferred to a $100 \mathrm{~mL}$ flask and diluted with double distilled water. This sample was further subjected to electrochemical analysis by standard addition method. The accuracy of this method expressed in terms of recoveries indicate that the proposed system proves efficient for the quantitation of GA in the green tea samples. The recovery range including the RSD for three parallel determinations is listed in Table 2. The observed recovery percentages of GA obtained in the samples taken were found to be satisfactory.

\section{Conclusions}

In summary, a simple electrochemical platform for fast, sensitive and selective determination of GA has been developed successfully. The sensor showed a good linear response in the range of $0.03 \mu \mathrm{M}$ to $480 \mu \mathrm{M}$ with a detection limit of $0.01 \mu \mathrm{M}$. The as-developed sensor showed good potential for the determination of GA in commercial tea samples. Therefore, a simple and reliable strategy has been proposed for fabricating Poly$\mathrm{Glu} / \mathrm{rGO}$ modified electrode with great potential for use as an electrochemical sensor for the determination of GA.

\section{Acknowledgements}

The authors gratefully acknowledge the support of this work by DST-SERB, New Delhi, India.

\section{References}

1. Mithilesh Singh, Alok Jha, Arvind Kumar, Navam Hettiarachchy, Ashiwini K R and Divya Sharma 2014 Influence of the solvents on the extraction of major phenolic compounds (punicalagin, ellagic acid and gallic acid) and their antioxidant activities in pomegranate aril J. Food Sci. Technol. 502017

2. Masamba K, Li Y, Hategekimana J, Liu F, Mal J and Zhong F 2015 Effect of Gallic acid on mechanical and water barrier properties of zein-oleic acid composite films J. Food Sci. Technol. 532227

3. Kim S H, Jun C D, Suk K, Choi B J, Lim H, Park S, Lee S H, Shin H Y, Kim D K and Shink TY 2006 Gallic Acid Inhibits Histamine Release and Pro-inflammatory Cytokine Production in Mast Cell Toxicol. Sci. 91123

4. Aruoma O I, Murcia A, Butler J J and Halliwellt B 1993 Evaluation of the Antioxidant and Prooxidant Actions of Gallic Acid and Its Derivatives J. Agric. Food Chem. 41 1880

5. Inoue M, Suzuki R, Sakaguchi N, Li Z, Takeda T, Ogihara Y, Jeang B Y and Chen Y 1995 Selective induction of cell death in cancer cells by Gallic Acid Biol. Pharm. Bull. 181526

6. Shahamirifard A S, Ghaedi M, Razmi Z and Hajati S 2018 A simple ultrasensitive electrochemical sensor for simultaneous determination of gallic acid and uric acid in human urine and fruit juices based on zirconia-choline chloride-gold nanoparticles-modified carbon paste electrode Biosens. Bioelectron. 11430

7. Xu W, Deng J, Qian Y, Hou X T, Zhu Z, Zhao M, Shang E, Qian D, Zeng H, Pang H and Duan J 2018 Simultaneous determination of kaempferol, quercetin, mangiferin, gallic acid, p-hydroxybenzoic acid and chlorpheniramine maleate in rat plasma after oral administration of MangGuo-Zhi-Ke tablets by UHPLC-MS/MS and its application to pharmacokinetics Biomed. Chromatogr. 32

8. Geim A K and Novoselov K S 2007 The rise of graphene Nat. Mater. 6183

9. Loh K P, Bao Q L, Eda G and Chhowalla 2012 Graphene oxide as a chemically tunable platform for optical applications Nat. Chem. 21015 
10. Narvaez E A, Pires L B, Gálvez A Z and Merkoçi A M 2017 Graphene-Based Biosensors: Going Simple $A d v$. Mater. 291604905

11. Justino C I L, Gomes A R, Freitas A C, Duarte A C and Rocha-Santos T A P 2017 Graphene based sensors and biosensors TrAC Trends Anal. Chem. 9153

12. Song Y, Luo Y, Chengzhou Zhu, He Li, Du D and Lin Y 2016 Recent advances in electrochemical biosensors based on graphene two-dimensional nanomaterials Biosens. Bioelectron. 76195

13. Guo Z, Li D, Luo X, Li Y, Zhao Q, Li M, Zhao Y, Sun $\mathrm{T}$ and Ma C 2017 Simultaneous determination of trace $\mathrm{Cd}(\mathrm{II}), \mathrm{Pb}(\mathrm{II})$ and $\mathrm{Cu}(\mathrm{II})$ by differential pulse anodic stripping voltammetry using a reduced graphene oxidechitosan/poly-l-lysine nanocomposite modified glassy carbon electrode J. Colloid Interface Sci. 49011

14. Kalimuthu P and Abraham John S 2011 Selective determination of 3,4 dihydroxyphenylacetic acid in the presence of ascorbic and uric acids using polymer film modified electrode J. Chem. Sci. 123349

15. Zhangyu Yu, Xiaochun Li, Xueliang Wang, Xinying Ma, Xia Li and Kewei Cao 2012 Voltammetric determination of dopamine and norepinphrine on a glassy carbon electrode modified with poly (L-aspartic acid) J. Chem. Sci. 124537

16. Pourjavadi A, Harzandi A $\mathrm{M}$ and Hosseinzadeh $\mathrm{H}$ 2004 Synthesis of a novel polysaccharide-based superabsorbent hydrogel via graft copolymerization of acrylic acid onto kappa-carrageenan in air Eur. Polym. J. 401363

17. Azadbakht A and Abbasi A 2016 Acriflavine immobilized onto polyethyleneimine-wrapped carbon nanotubes/gold nanoparticles as an electrochemical sensing platform J. Chem. Sci. 128257

18. Zanta C L P S and Huitle M C A 2007 Electrochemical behaviour of platinum at polymer-modified glassy carbon electrodes J. Chem. Sci. 119283

19. Barrientos H, Moggio I, Arias-Marin E, Ledezma A and Romero J 2007 Layer-by-layer films of enzymatically synthesized poly(aniline)/bacterial $\operatorname{poly}(\gamma-$ glutamic acid) for the construction of nanocapacitors Eur. Polym J. 431672

20. Wu S, Zeng F, Zhu H, Luo S, Ren B and Tong Z 2005 Mesomorphous Structure and Macroscopic Patterns Formed by Polymer and Surfactant from Organic Solutions Macromolecules 389266

21. Yoshikawa M, Murakoshi K, Kogita T, Hanaoka K, Guiver M D and Robertson G P 2006 Chiral separation membranes from modified polysulfone having myrtenalderived terpenoid side groups Eur. Polym. J. 422532

22. Wu S, Zeng F, Zhu H and Tong Z 2006 Formation of Microscopic Ordering and Macroscopic Patterns in Solid Polyacrylate-Tetraoctylammonium Bromide Films Macromolecules 392606

23. Xu J, Zeng F, Wu S, Hou C, Liu X and Tong Z 2007 Gold nanoparticles bound on microgel particles and their application as an enzyme support Nanotechnology 1826

24. Audic J L and Chaufer B 2005 Influence of plasticizers and crosslinking on the properties of biodegradable films made from sodium caseinate Eur. Polym. J. 411934

25. Porcar I, Codoner A, Gomez CM, Abad C and Campos A 2004 Interactions of quinine with polyacrylic and
poly-L-glutamic acids in aqueous solutions Eur. Polym J. 40819

26. Wu S, Lu J, Zeng F, Chen Y and Tong Z 2007 Photo induced Formation of Microscopic Ordering and Macroscopic Pattern in Spiropyran-Containing PolyacrylateTetraoctylammonium Bromide Films Macromolecules 405060

27. Liu Y, Dong X and Chen P 2012 Biological and chemical sensors based on graphene materials Chem. Soc. Rev. 39 3157

28. Yu A M and Chen H Y 1997 Electrocatalytic oxidation and determination of ascorbic acid at poly (glutamic acid) chemically modified electrode Anal. Chim. Acta 344181

29. Zhang Y, Luo L, Ding Y, Liu and Qian Z 2010 A highly sensitive method for determination of paracetamol by adsorptive stripping voltammetry using a carbon paste electrode modified with nanogold and glutamic acid Microchim. Acta $\mathbf{1 7 1} 133$

30. Ho G H, Ho T I and Hsieh K H $2006 \gamma$-polyglutamic acid produced by Bacillussubtilis (natto): structural characteristics, chemical properties, and biological functionalities J. Chin. Chem. Soc. 531363

31. Shih L and Van Y T 2001 The production of poly( $\gamma$-glutamic acid) from microorganisms and its various applications Biores. Technol. 79207

32. Shahriary L, Anjali A and Athawale 2014 Graphene Oxide Synthesized by using Modified Hummers Approach International J. Renew. Energy Environ. Eng. 2356

33. Benvidi A, Yazdanparast S, Rezaeinasab M, Tezerjani MD and Abbasi S 2018 Designing and fabrication of a novel sensitive electrochemical apta sensor based on poly (L-glutamic acid)/MWCNTs modified glassy carbon electrode for determination of tetracycline $J$. Electroanal. Chem. $\mathbf{8 0 8} 311$

34. Toh S Y, Loh K S, Kamarudin S K and Daud W R W 2014 Graphene production via electrochemical reduction of graphene oxide: Synthesis and characterization Chem. Eng. J. 251422

35. Liu X, Luo L, Ding Y and Ye D 2011 Poly-glutamic acid modified carbon nanotube-doped carbon paste electrode for sensitive detection of L-tryptophan Bioelectrochemistry $\mathbf{8 2} 38$

36. Santos D P, Zanoni M V B, Bergamini M F, Ana and Victor M C 2008 Poly(glutamic acid) nanofibre modified glassy carbon electrode: Characterization by atomic force microscopy voltammetry and electrochemical impedance Electrochim. Acta $\mathbf{5 3} 3991$

37. Mahshidab S S, Mahshid S, Dolatia A, Ghorbania M, Yang L, Luo S, Cai Q 2013 J. Alloys Comp. 554169

38. Bui M N, Li C A and G H Seong 2012 Electrochemical detection of dopamine with poly-glutamic acid patterned carbon nanotube electrodes Bio. Chip J. 6149

39. Aoyama S, Ismail I, Park Y T, Yoshida Y, Macosko C W and Ougizawa T 2018 Polyethylene Terephthalate/Trimellitic Anhydride Modified Graphene Nanocomposites ACS Appl. Nano Mater. 111

40. Juliano A B, Sergio H T, Marcelo N and Henrique E T 2017 Electrocatalytic activity in sensing of nitrite by films produced by electropolymerization of $[\mathrm{Fe}(\mathrm{Brph}-$ tpy)2] $^{2+}$ J. Coord. Chem. 71137 
41. Ashok Kumar S, Tang C F and Chen S M 2008 Electroanalytical determination of acetaminophen using nano- $\mathrm{TiO}_{2} /$ polymer coated electrode in the presence of dopamine Talanta 76997

42. Manikandan R, Deepa P N and Sriman Narayanan S 2017 Fabrication and characterization of poly 2-napthol orange film modified electrode and its application to selective detection of dopamine J. Solid State Electrochem. 213567

43. Beitollahi H and Nejad F G 2016 Graphene Oxide/ZnO Nano Composite for Sensitive and Selective Electrochemical Sensing of Levodopa and Tyrosine Using Modified Graphite Screen Printed Electrode Electroanalysis $\mathbf{2 8} 2237$

44. Souza L P, Calegari F, Zarbin A J G, Junior L H M and Bergamini M F 2011 Voltammetric determination of the antioxidant capacity in wine samples using a carbon nanotube modified electrode J. Agric. Food Chem. 59 7620

45. Hamid R A and Newair F E 2013 Adsorptive stripping voltammetric determination of gallic acid using an electrochemical sensor based on polyepinephrine/glassy carbon electrode and its determination in black tea sample J. Electroanal. Chem. 70432

46. Luo J H, Li B L, Li N B and Luo H Q 2013 Sensitive detection of gallic acid based on polyethyleneiminefunctionalized graphene modified glassy carbon electrode Sens. Actuat. B: Chem. 18684

47. Sanz V C, Mena M L, Cortes A G, Sedeno P Y and Pingarron J M 2005 Development of a tyrosinase biosensor based on gold nanoparticles-modified glassy carbon electrodes: application to the measurement of a bioelectrochemical polyphenols index in wines Anal. Chim. Acta 5281

48. Sangeetha N S and Narayanan S 2014 A novel bimediator amperometric sensor for electrocatalytic oxidation of gallic acid and reduction of hydrogen peroxide Anal. Chim. Acta 82834

49. Huang Y, Wen W L, Lu Bo Chen, Min Wu and Shu-guang Li 2015 Determination of 13 Phenolic Compounds in Rice Wine by High-Performance Liquid Chromatography Food Anal. Methods $\mathbf{8} 825$ 